\title{
Retrofit and Renovation of Concrete Bridges with Fibre Reinforced Polymer (FRP): The Third Alternative
}

\author{
Gerrit Visser ${ }^{1, *}$, Kees Van Ijselmuijden ${ }^{2}$, Ernst Klamer $^{3}$, and Gideon Van Zij1 ${ }^{4}$ \\ ${ }^{1}$ Royal HaskoningDHV, Bridge Engineer, International Co-Ordinator: Structures Knowledge Group, Pietermaritzburg, South Africa \\ ${ }^{2}$ Royal HaskoningDHV, Bridge Engineer, Amsterdam, Netherlands \\ ${ }^{3}$ Royal HaskoningDHV, Bridge Engineer, Nijmegen, Netherlands \\ ${ }^{4}$ Stellenbosch University, Head, Division of Structural Engineerin with Fibreg and Civil Engineering Informatics, Stellenbosch \\ University, South Africa
}

\begin{abstract}
This paper presents Fibre Reinforced Polymer (FRP) as a third alternative construction material worth considering when retrofitting a bridge structure. FRP offers the following advantages: lighter than steel and concrete, non-corrosive, low in maintenance, stronger than structural steel and fatigue resistant. FRP has been used in Europe and more specifically in the Netherlands for almost 20 years in the retrofitting of road bridges, in new pedestrian bridges, road bridges and lock doors for sluices. The Netherlands has recently developed the updated Dutch Design Code CUR Recommendation 96, which was published in December 2017. The CUR Recommendation 96 will form the basis for developing the Eurocode FRP which is expected to be published between 2020 and 2025. The use of FRP in retrofitting of bridges is presented using examples which demonstrate how existing concrete decks, and steel and concrete substructures could be retained by the use of FRP in the retrofitting solution. Due to FRP being a relatively unknown material within the South African bridge design field, the authors have embarked on an awareness campaign targeting academics, government bodies, suppliers, manufacturers and contractors, with the aim of presenting FRP as a third alternative construction material in the South African bridge fraternity.
\end{abstract}

\section{Introduction}

FRP has been used in Europe and more specifically in the Netherlands for almost 20 years in the retrofitting of road bridges as well as in the construction of new pedestrian bridges, road bridges and lock doors for sluices. The Netherlands has recently developed the updated Dutch Design Code CUR Recommendation 96 (fig. 1), which was published in December 2017. CUR Recommendaton 96 is the Dutch FRP design code for infrastructure and will form the basis for developing the Eurocode FRP (which is expected to be published between 2020 and 2025 (EUR 27666 EN 2016).

This paper proposes Fibre Reinforced Polymer (FRP) as an alternative construction material for use in both the retrofitting of existing bridges and the construction of new bridges in South Africa.

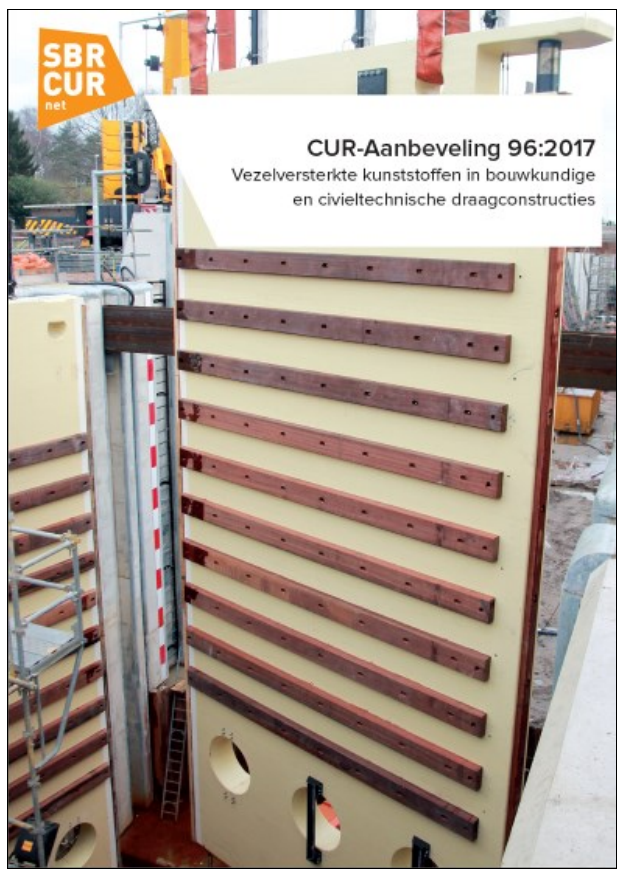

Fig. 1. Dutch design code for FRP CUR Recommendation 96:2017

\footnotetext{
* Corresponding author: gerrit.visser@rhdhv.com
} 


\section{The Third Construction Material: Fibre Reinforced Polymer (FRP)}

FRP is a third alternative construction material worth considering when retrofitting a bridge structure, with concrete and structural steel being the two conventional materials. It is believed that FRP is possibly underutilised in the bridge design domain, due to:

- FRP being a relatively unknown material to designers in this domain,

- The misconception that FRP is more expensive than concrete and structural steel,

- The belief that FRP is not as durable and

- The belief that use of FRP would entail more complicated design work.

However, FRP offers the following advantages:

- Lightweight material (2 to 3 times lighter than steel structures and up to 10 times lighter than concrete structures),

- Non-corrosive,

- Low in maintenance,

- Stronger than structural steel,

- Fatigue resistant,

- Good in absorbing impact energy,

- Long lifespan,

- Sustainable material and

- Can be formed to suit almost any architectural shape.

As can be seen in fig. 2, FRP has been used since 1940 in the aircraft industry and after that also in defence, space, yachts, sporting goods, automotive industry and now also in the buildings and infrastructure domain. As a matter of interest, FRP is used in several items people use on a daily basis, e.g. tennis rackets, hockey sticks, helmets, bicycles, surfboards, etc.

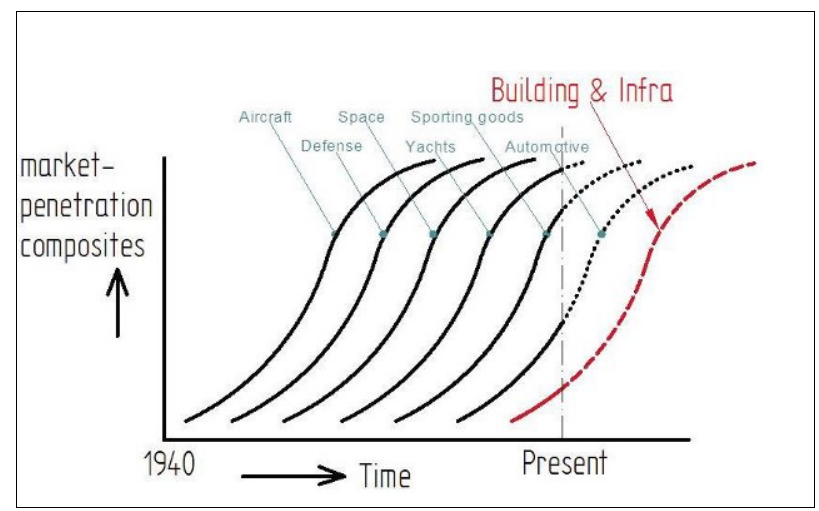

Fig. 2. FRP applications since 1940

An FRP composite is an advanced composite system consisting of layers of fibres embedded in a matrix or resin, creating a light, strong, durable material. The fibres are used for the mechanical properties like strength and stiffness while the resin supports the fibres under pressure and ensures that all the fibres work together. The resin also provides chemical and UV resistance and can also be used to provide a specific colour to the structure.

There are a number of available methods to produce FRP, but the two most common in infrastructure are the pultrusion method and vacuum infusion method.
Pultruded elements can be ordered in standard profiles (I, U, L-beams) and are limited in size and therefore limited in span. Vacuum infusion needs a mould, to shape the structure. This method gives one the freedom to form any shape and normally requires less connections than pultruded structures in the final structure.

In Europe more than 600 bridges have been built using FRP material. Some examples include:

i. The Nelson Mandela Bridge in Alkmaar (fig.3) this is an FRP table bridge with $22,5 \mathrm{~m}$ spans. The bridge has 2 traffic lanes and was designed to withstand Eurocode traffic loading. Due to the lightweight deck structure the counter weights of the deck (red boxes behind the piers) could be reduced compared to a steel deck.

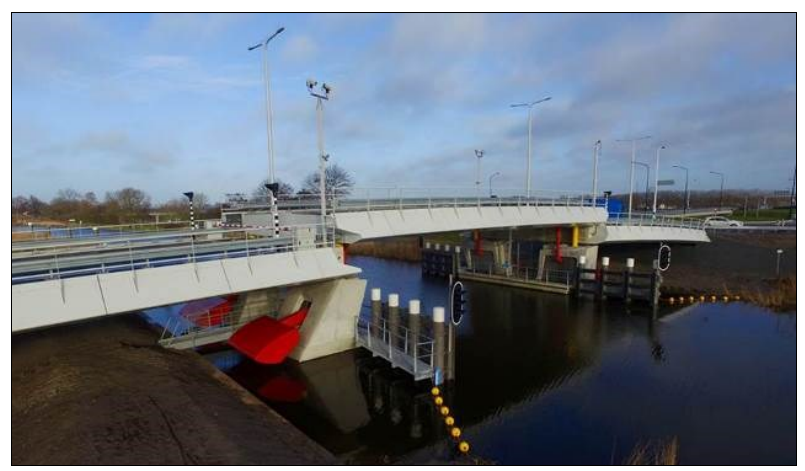

Fig. 3. Nelson Mandela Bridge in Alkmaar, Netherlands

ii. Dragonfly Bridge, Harderwijk, Netherlands (fig. 4) this pedestrian bridge in the city of Harderwijk was constructed with FRP. The main reason for using FRP was the freedom the material offers to form the dragonfly shape of the deck. Additional advantages are the lighter abutments and foundations due to the lightweight of the deck, as well as the faster construction time required.

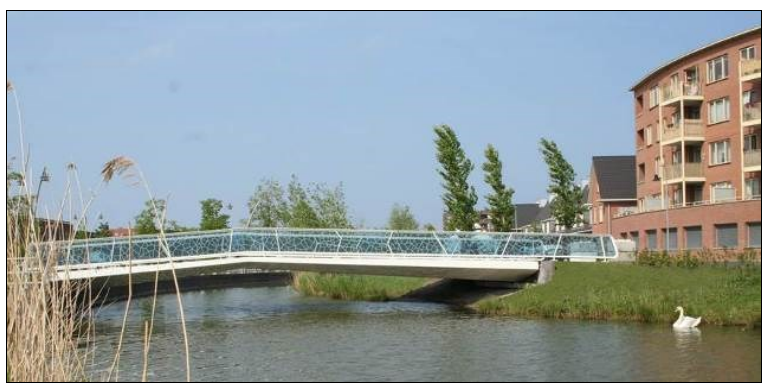

Fig. 4. Dragonfly Bridge, Harderwijk, Netherlands

iii. Bridge Paradis, Bergen, Norway (fig. 5) - The bridge in Bergen is a $42 \mathrm{~m}$ span pedestrian bridge and the superstructure is entirely constructed out of FRP. FRP was the most appropriate construction material due to the fact that (a) the bridge crosses a busy light rail track and as such a low maintenance structure was required, (b) the deck had to be lightweight so that it could be lifted into place and (c) the occupation for the placing of the deck was only available for 72 hours. 


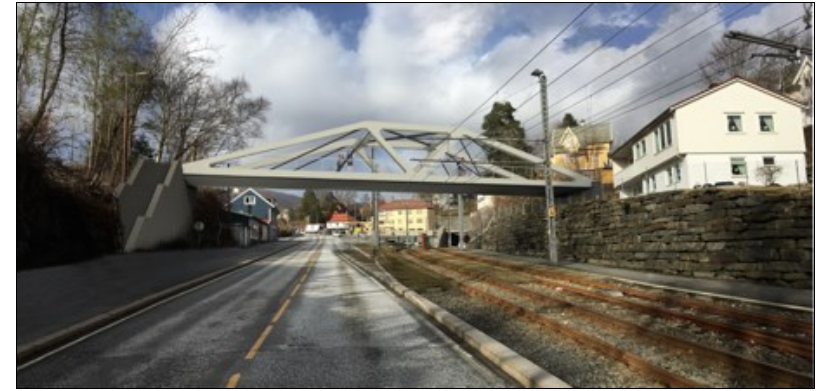

Fig. 5. Bridge Paradis, Bergen, Norway

The following section will document three European examples of the use of FRP - specifically chosen to highlight advantages of the use of FRP.

\section{Advantages of FRP - Practical Examples from Europe}

The use of FRP in retrofitting of bridges are presented using two examples from Europe, namely the Doesbrug Bridge and the Westervoort Cycle Bridge. Examples of edge elements on road bridges are also presented.

The examples demonstrate how the existing steel or concrete substructures can be retained through the use of FRP in the retrofitting solution when widening bridges, replacing existing decks and providing deck edge elements to improve the bridge appearance.

\subsection{Doesbrug Bridge}

\subsubsection{Background}

The Doesburg Bridge, fig. 6, spans the IJssel River in the Netherlands. The Doesburg Bridge has a total length of $138 \mathrm{~m}$, with a centre steel arch span of $89 \mathrm{~m}$, and was built in 1951. The deck comprises a composite steel and concrete slab. The deck has two traffic lanes in between the arches and two cycling paths outside the arches.

This bridge is used as an example to demonstrate the lightweight advantage that FRP offers, as opposed to the conventional, heavier concrete material. FRP was successfully used as part of the structural solution in reducing the weight of the deck replacement and as a result extended the lifespan of the bridge.

\subsubsection{Problem Statement}

In 2014, it was decided that the Doesburg Bridge needed to be retrofitted to meet the increased traffic load requirements and to extend the life span by 30 years.

The existing bridge had to be structurally upgraded to meet the requirements of the current Eurocode Traffic Loads, as well as the Dutch Code NEN 8700 for the assessment of existing structures. A structural analysis was carried out to determine the scope of the renovation required. The analysis indicated that the two concrete decks both inside and outside the steel arches had to be replaced or strengthened to resist the latest traffic loads, or alternatively load limitations would need to be introduced on the bridge. The latter proposal was not acceptable to the client.

Due to the fact that the Doesbrug Bridge is on one of the main access roads into the City of Doesbrug, it was a requirement of the owner (Dutch Ministry of Infrastructure and Water Management) that the bridge remain accessible to emergency services and public transport during the entire renovation. One possible solution was to replace the northern cycling path's deck first and then use it as traffic accommodation for the emergency vehicles and public transport while the remainder of the decks were being replaced.

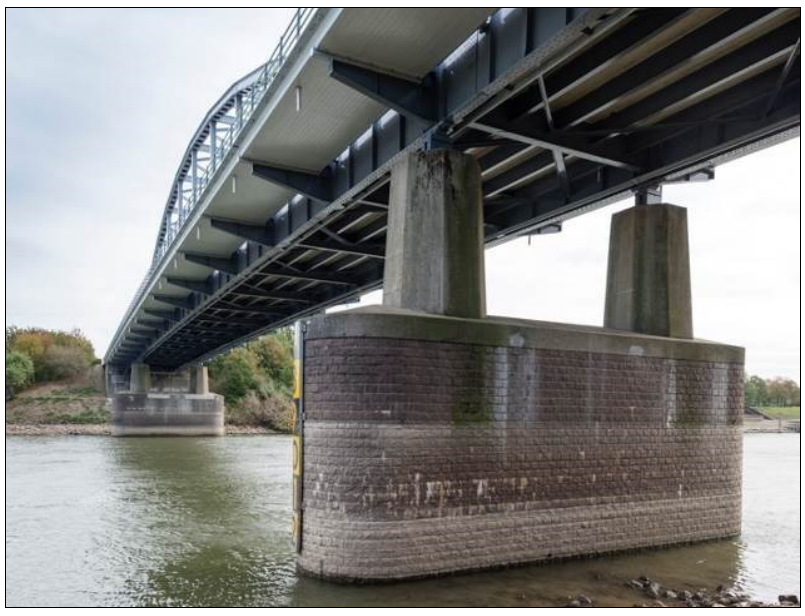

Fig. 6. FRP bridge deck cycling paths (Source: Rijkswaterstaat. Photographer: Thea van den Heuvel/DAPh)

\subsubsection{Proposed Retrofitting}

The following three possible solutions were investigated:

- Replacing all existing decks with concrete decks as was per the original design

- Replacing all existing decks with FRP decks

- Replacing the centre deck with a concrete deck and the outside cycling deck with an FRP deck.

The investigation showed that, taking the increased traffic loads into consideration, as well as meeting the requirement of keeping one of the cycle paths accessible for emergency services and public transport, proposal A (concrete decks) would render a heavier concrete structure that would result in an increase in load on the steel substructure. As a result, the required steel strengthening would increase significantly and would incur additional cost. Proposal B (FRP decks) would result in a significant reduction of dead weight. This would, however, be a more costly solution. Proposal C rendered a more cost efficient solution by reducing the dead weight enough so that the supporting steel structure did not need extra strengthening. It was therefore decided to only replace the cycling paths with an FRP bridge deck (fig. 7) and the remainder of the decks with concrete. In this case, specifically Glass Fibre Reinforced Polymer (GFRP) was chosen. 


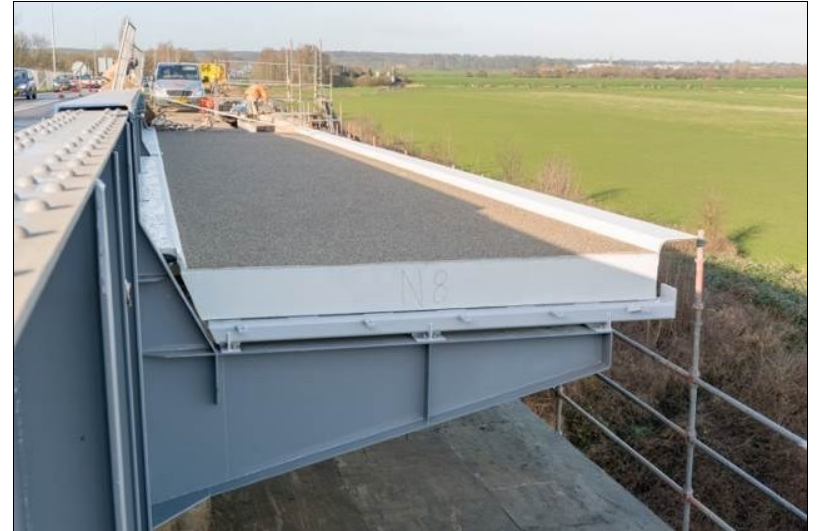

Fig. 7. FRP bridge deck panel installed (Source: Rijkwaterstaat. Photographer: Thea van der Heuvel/DAPh)

For tendering purposes, a preliminary design was prepared for the replacement of the concrete cycling paths deck with an FRP deck. In 2015 the construction work was put out to tender and a construction company experienced in FRP work in Europe won the tender.

The FRP deck panels were produced as prefabricated FRP panels using the vacuum-injection technique. The deck panels were prefabricated in 14 elements of about 16,5 $\mathrm{m} \mathrm{x} \mathrm{3,7} \mathrm{m}$ and 2 elements of 25,5 $\mathrm{m} \times 3,7 \mathrm{~m}$. A non-slip layer was applied on top of the panels. The weight of the FRP panels was approx. 1,1 $\mathrm{kN} / \mathrm{m}^{2}$, including the non-slip layer. Besides the advantage of the low weight, FRP also offered the advantage of producing the deck off-site under controlled conditions (fig. 8), as well as the advantage of placing the deck with a minimal traffic disturbance.

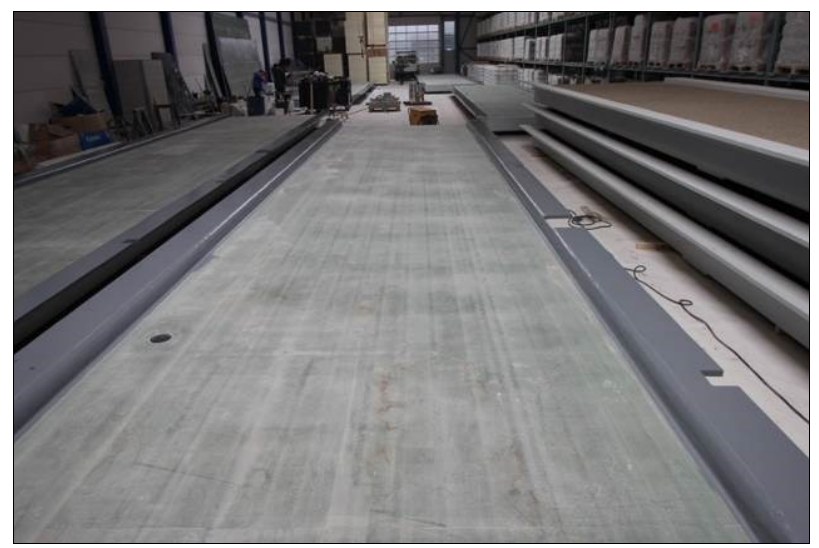

Fig. 8. Production of FRP bridge deck panel (Source: Composite Structures)

\subsection{Westervoort Cycle Bridge}

\subsubsection{Background}

The Westervoort Cycle Bridge (fig. 9) is a reinforced concrete bridge for cyclists that was built in the 1980s. The bridge has 3 spans of $11 \mathrm{~m}, 16 \mathrm{~m}$ and $11 \mathrm{~m}$.

The deck is a U-beam with the parapets as the main structural beam connected by the floor slab. The main advantage of the U-beam deck type is the reduced vertical clearance requirements from the deck soffit to the road below.

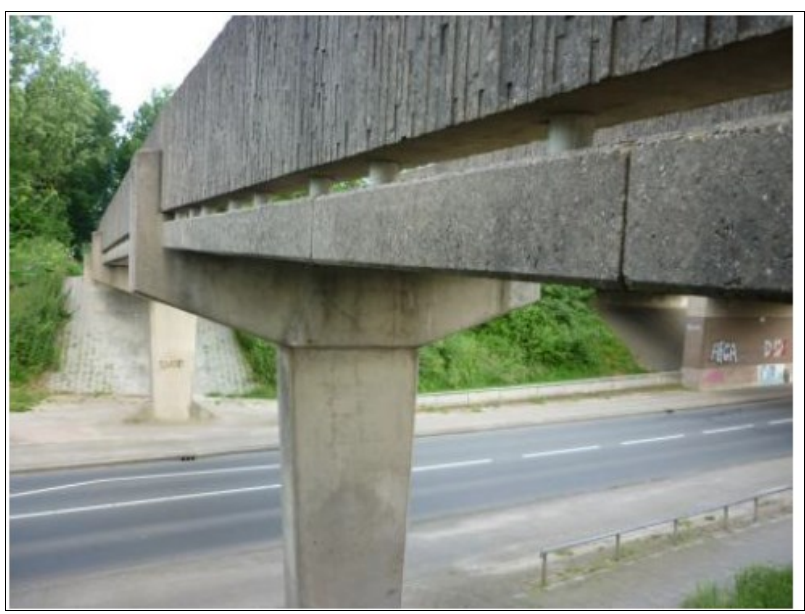

Fig. 9. Side elevation of existing Westervoort Cycle Bridge

The deck showed some durability failures after about 35 years - see figs. 10,11. This was due to chloride ingress into the concrete that caused the reinforcing to corrode. These defects resulted in the structural capacity of the bridge being compromised to the extent that the bridge had to be closed to the public. The same deterioration was not experienced on the substructure, which structurally was still in a good condition.

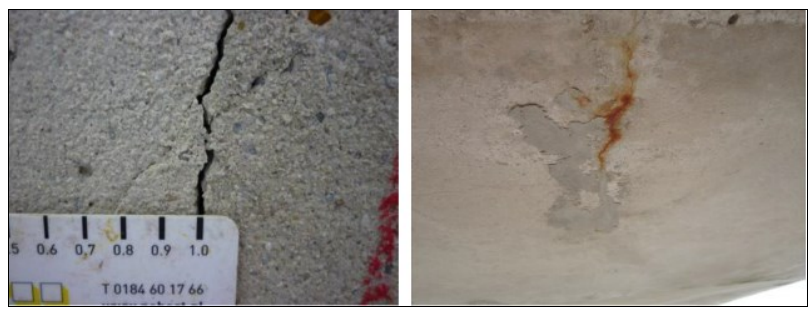

Fig. 10. Cracks in the Westervoort Cycle Bridge deck soffit
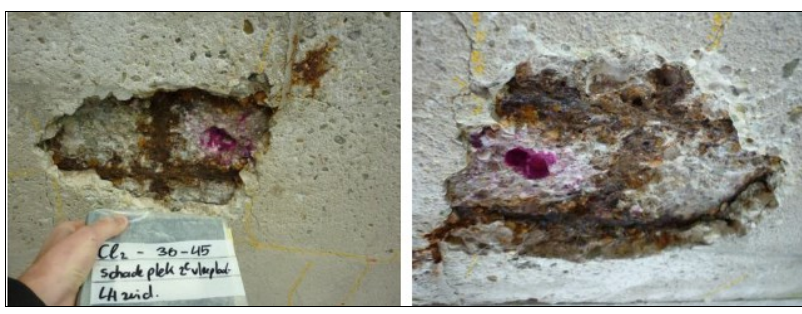

Fig. 11. Delamination of concrete cover and corrosion of reinforcing due to chloride-induced corrosion

This bridge is used as an example to demonstrate both the lightweight advantage, as well as the durability advantage that FRP offers, as opposed to the higher weight and increased maintenance needs of a steel and concrete structure in an aggressive environment. FRP was successfully used in reducing the weight and limiting the maintenance requirements of this bridge. 


\subsubsection{Problem Statement}

The local Municipality appointed RHDHV to design the replacement deck for this bridge. The existing substructure was to be retained, the replacement deck was to be widened to match the approaching fast track cycle path (fig. 12) and the construction was to have minimal impact on the existing road traffic.

There was no as-built information of the existing bridge available. It was therefore decided to analyse the existing bridge and compare the results with that of the proposed solution. The aim was to come up with a solution that would have the same, or less of an effect on the existing substructure.

The analysis of the existing structure was done using the codes applicable in 1980. A traffic load of $4,0 \mathrm{kN} / \mathrm{m}^{2}$ was used and the unit weight for concrete used was 2400 $\mathrm{kg} / \mathrm{m}^{3}$. This resulted in a total deck loading of 732 $\mathrm{kg} / \mathrm{m}^{2}$.

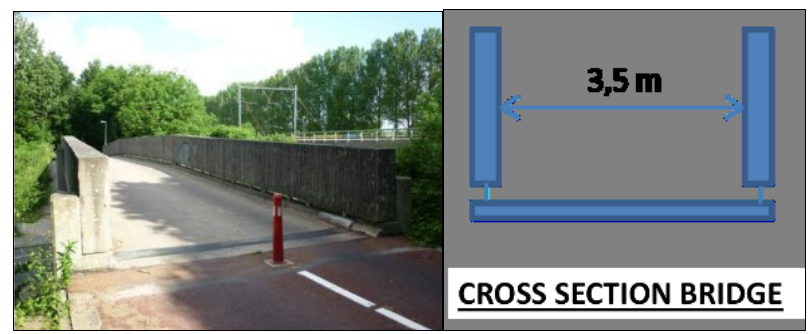

Fig. 12. Cross section of the existing cycle bridge deck

\subsubsection{Proposed Retrofitting}

Due to the lightweight advantage of the FRP material, the quicker installation time associated with FRP decks and the superior durability it offers compared to structural steel, it was decided to seek a solution involving a FRP deck replacement. This would imply that the existing substructure could be re-used and that the FRP deck could be placed with minimum disruption to the road traffic.

The proposed deck consisted of a similar U-shape to that of the existing deck, but was made out of FRP. The upstand elements (fig. 13) were proposed as FRP trusses and the bottom deck also was an FRP element.

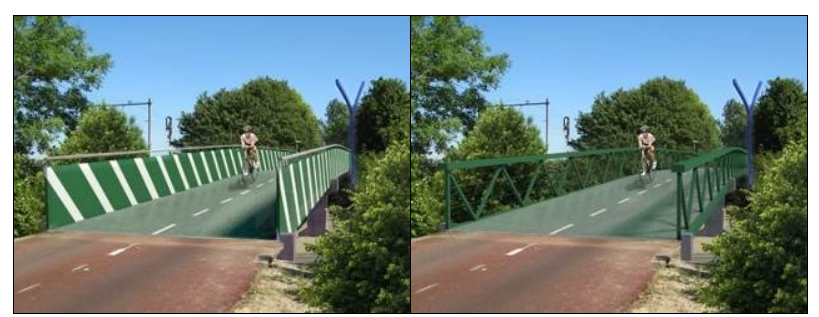

Fig. 13. A closed and open solution for a FRP Deck

The weight of the FRP deck solution was in the order of $80-130 \mathrm{~kg} / \mathrm{m}^{2}$, which is about $11-17 \%$ that of the existing concrete deck. This lighter deck made it possible to realise the wider deck and also accommodate the latest pedestsrian traffic loadings. The loading on the substructure was reduced by $44 \%$. The implication was that the substructure did not need to be strengthened to receive the new, wider FRP deck.

It is anticipated that the lifespan of the FRP deck will be significantly extended.

\subsection{Examples of FRP Edge Elements on Road Bridges}

\subsubsection{Background}

In the Netherlands edge elements are used on viaducts and bridges as cladding to house services like water mains and communication cables. Conventionally, these edge elements have been constructed out of concrete and later out of steel or aluminium. Since the year 2000 FRP has also been used to construct these edge elements.

The examples of edge elements demonstrate how the lightweight and freedom to manufacture it in any shape that FRP offers are used to host services and at the same time enhance the appearance of the bridge.

\subsubsection{Examples}

Figure 14 shows an FRP edge element during construction. Note the steel frames that hold the FRP cladding in place, as well as the space available for services. The services can be held in place by the steel brackets or attached to the edge of the concrete deck.

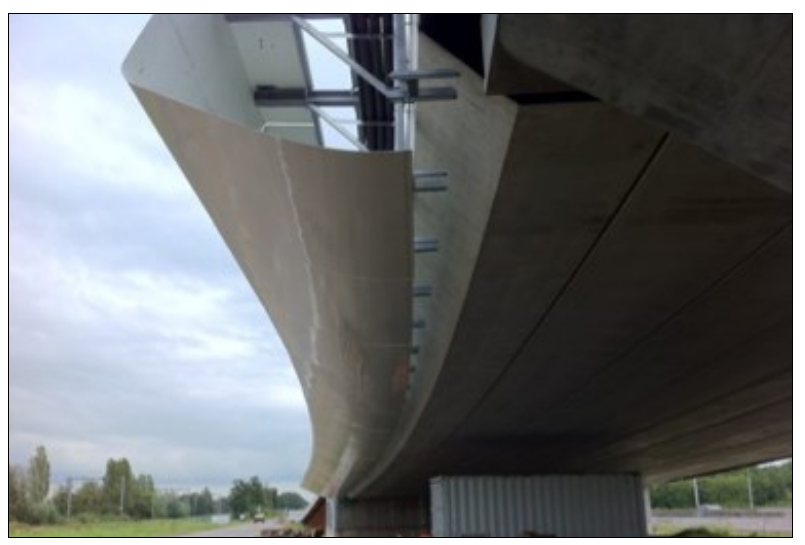

Fig. 14. FRP edge element with inspection path

Figures 15 and 16 shows a completed edge element on a different bridge deck, in Zaandam, Netherlands. The deck is a beam-and-slab deck which can be very utilitarian in appearance, but as demonstrated by fig. 16, the FRP edge element provides a neat solution that also enhances the appearance of the bridge.

As can be seen in fig. 17, the edge elements can also be made with translucent parts. In the daylight the translucent parts appear smooth and are the same colour as the rest of the element, but at night time the LED lights behind the translucent part illuminate the structure. 


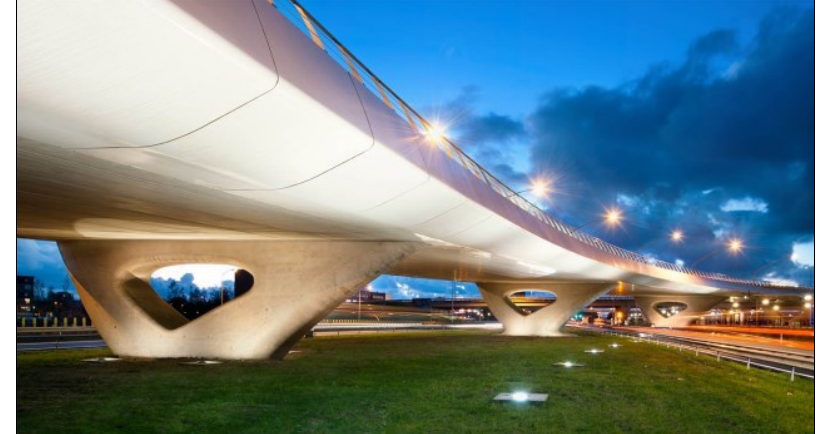

Fig. 15. Concrete deck with FRP edge elements
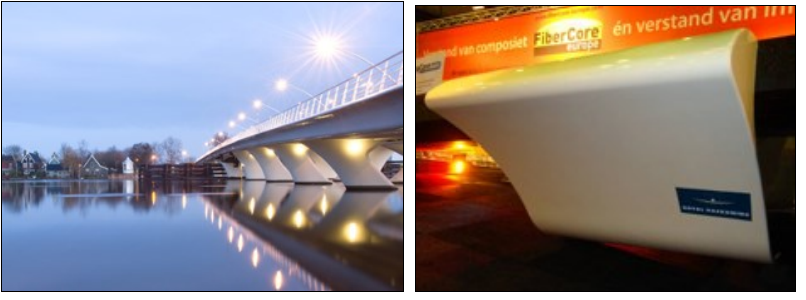

Fig. 16. Julia Bridge, Zaandam, Netherlands
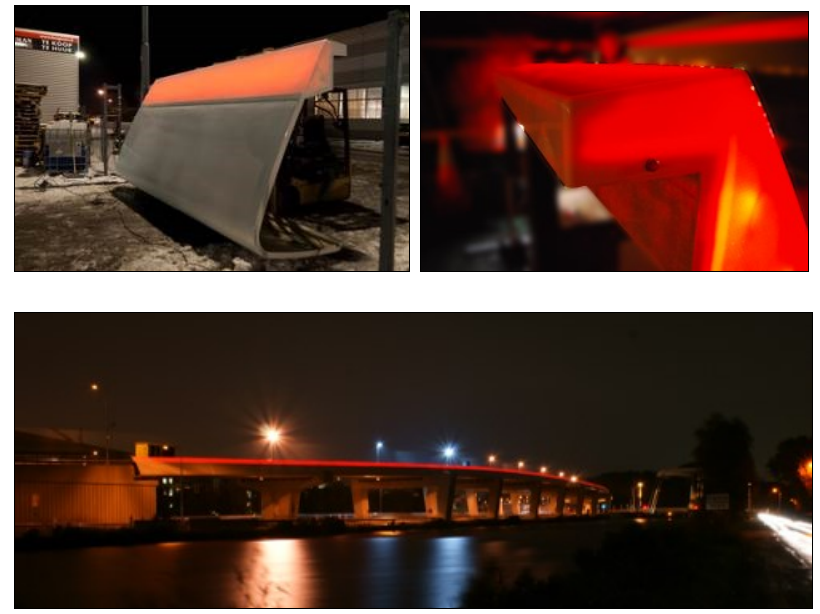

Fig. 17. Examples of translucent FRP panels with LED lights

Figures 18 and 19 illustrate how an existing utilitarian-looking bridge can be modified with the edge elements to enhance its appearance.

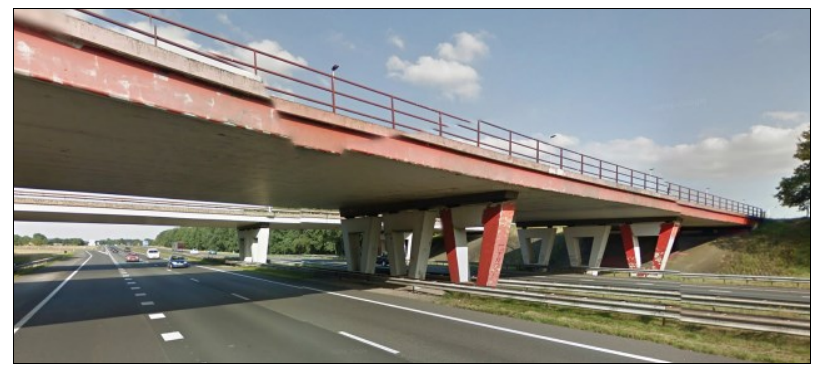

Fig. 18. Existing utilitarian-looking bridge

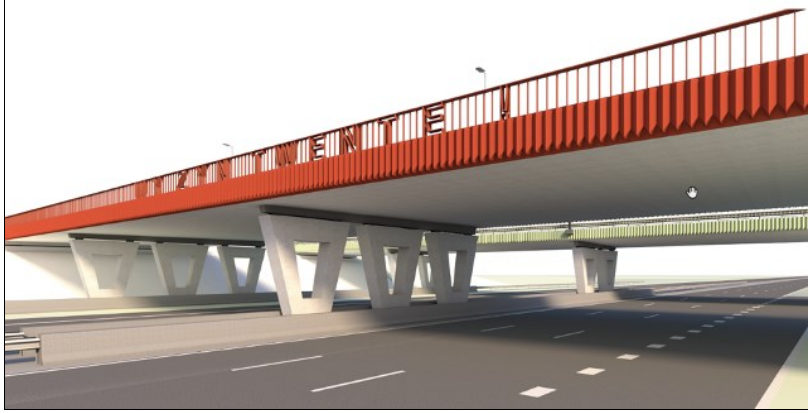

Fig. 19. Visualisation of the same bridge with edge elements

\section{Introducing FRP as a Third Alternative to the South African Market}

Due to FRP being a relatively unknown material within the South African bridge design field, the authors embarked on an awareness campaign targeting academics, government bodies, suppliers, manufacturers and contractors, with the aim of presenting FRP as a third, alternative construction material in the South African bridge fraternity.

\subsection{FRP Awareness Campaign: Team, Goals and Targeted Communities}

RHDHV put together a team of three members, namely Maurice Kardas, Kees Van Ijselmuijden and Gerrit Visser, to visit role players in the South African bridge fraternity with the goal to determining the interest in, and viability of FRP as a third construction material to be used in bridge design.

The FRP Awareness campaign took place from 9-19 July 2017. The team met with staff from Stellenbosch University, the South African National Roads Agency Limited (SANRAL), Provincial Administration of KwaZulu of Natal: National Department of Transport, Provincial Administration of Western Cape: Department of Transport, Municipality of Johannesburg, Municipality of Durban, local suppliers of FRP, local manufacturers of FRP and bridge building contractors.

During the campaign FRP was presented as the third construction material and European examples were used to demonstrate its uses and advantages. It was also discussed how the material could be used in the South African labour intensive market and how it could be used by emerging contractors.

\subsection{Reception of FRP as a Third Alternative Construction Material within the South African Bridge Fraternity}

The information regarding FRP and its uses as a third construction material was well received by all consulted. The relevant role players agreed that the benefits and advantages realised in the European examples could also be realised in the South African market and that it was a material worth considering where applicable.

There were concerns raised about the lack of experience with FRP as a bridge building material in 
South Africa, but this was not believed to be a major problem as the product has already proven itself in the European market. RHDHV offered to prepare a set of Committee of Land Transport Officials (COLTO) guideline documentation with relevant quality assurance checks that can be used in the construction documentation. Designs incorporating FRP would be possible using existing international codes and would be made easier once the CUR Recommendation 96 has been incorporated in the Eurocodes.

\section{Conclusion}

The use of FRP as structural material for bridge retrofitting and renovation has been presented. Actual case studies of a road bridge and a cyclist pass-over bridge illustrate the appropriate application fields for this relatively new construction material. The following conclusions are drawn:

- Life span extension of bridges is possible with an FRP deck replacing the existing $\mathrm{RC}$ deck or parts of it, whilst retaining the substructure and accommodating increased standardised traffic loads.

- Lowest direct cost of the renovation intervention is possible using an FRP deck to replace the old deck or parts of it, by careful consideration of partial replacement. This is enabled by retaining the existing substructure, which would otherwise have to be strengthened to bear increased superstructure weight of traditional material and increased traffic load.

- Interruption of traffic during the intervention is reduced, by less construction provision required to place the lighter FRP deck superstructure.

- Cost of maintenance and repair is believed to be less for FRP structures, given the exclusion of steel and associated avoidance corrosion deterioration.

- Improved aesthetical appearance of bridges is enabled by light FRP edge panels to hide services on new or existing bridges, without significant added weight. Translucent panels enable aesthetically pleasing illumination. Freedom of FRP element form is allowed by vacuum infusion methods.

The evidence of longevity of FRP structures or structural elements remains to be confirmed, given the recent implementation of the presented cases over the past years. Based on material characteristics it is expected that the material will serve the intended added service life, even in aggressive environments of salt deicing practice, or ultra violate exposure. Fatigue behaviour remains an area of research.

\section{References}

CUR 96 (2017): Recommendation 96: Fibre-reinforced polymers in civil load-bearing structures, CUR Commission C124, CUR, Gouda, The Netherlands (in Dutch)

EN 1991-2: 2003. Actions on structures - Part 2: Traffic load on bridges, European Committee for Standardisation

EUR 27666 EN 2016. Prospect for new guidance in the design of FRP, Joint Science Research Centre, European Commission, $176 \mathrm{pp}$.

NEN 8700: 2012. Beoordelen van bestaande Constructies 